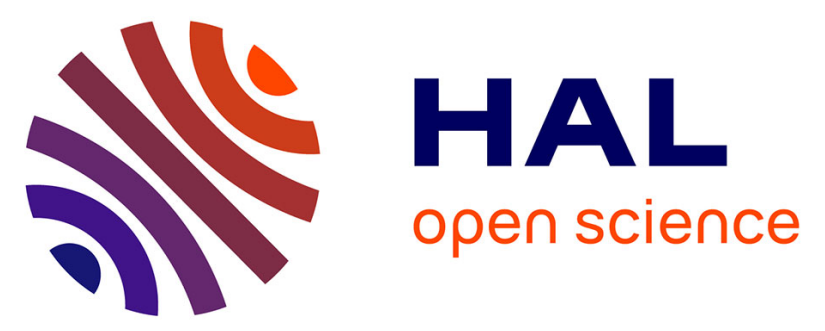

\title{
A simplified modelling approach for pesticide transport in a tile-drained field: the PESTDRAIN model
}

F. Branger, J. Tournebize, N. Carluer, C. Kao, Isabelle Braud, M. Vauclin

\section{To cite this version:}

F. Branger, J. Tournebize, N. Carluer, C. Kao, Isabelle Braud, et al.. A simplified modelling approach for pesticide transport in a tile-drained field: the PESTDRAIN model. Agricultural Water Management, 2009, 96 (3), p. 415 - p. 428. hal-00547576

\section{HAL Id: hal-00547576 \\ https://hal.science/hal-00547576}

Submitted on 16 Dec 2010

HAL is a multi-disciplinary open access archive for the deposit and dissemination of scientific research documents, whether they are published or not. The documents may come from teaching and research institutions in France or abroad, or from public or private research centers.
L'archive ouverte pluridisciplinaire HAL, est destinée au dépôt et à la diffusion de documents scientifiques de niveau recherche, publiés ou non, émanant des établissements d'enseignement et de recherche français ou étrangers, des laboratoires publics ou privés. 


\title{
A simplified modelling approach for pesticide transport in a tile-drained field: The PESTDRAIN model
}

\author{
F. Branger, J. Tournebize† N. Carluerł C. Kao§, I. Braud, and M. Vauclin॥
}

\begin{abstract}
The paper presents a simplified model called PESTDRAIN. It simulates pesticide transport in a subsurface tile-drained field. It computes surface runoff and tile-drainage flow rates, along with the associated pesticide concentrations, with a variable event-driven time step. PESTDRAIN consists of three coupled modules: SIDRA, SIRUP and SILASOL. SIDRA and SIRUP are the water flow simulation modules in the saturated and unsaturated zones, respectively. SIDRA follows a simplified physically based approach while SIRUP follows a conceptual capacitive approach. SILASOL is the solute transport module for both the saturated and unsaturated zones and is based on transfer functions. It includes simple representations of adsorption and degradation of pesticides.

PESTDRAIN was tested on field data sets collected for three drainage seasons at the La Jaillière experimental site in north-western France, for the wheat herbicides isoproturon (IPU) and diflufenican (DFF). After model calibration, relative errors for drainage and surface runoff flows over the season were $14 \%$ and $4 \%$, respectively, and the NashSutcliffe efficiency coefficient $\left(N_{\text {eff }}\right)$ value for drainage discharge was 0.58. A fair reproduction of a high temporal resolution IPU concentration data set in drainage discharge was also obtained $\left(N_{\text {eff }}=0.28\right)$. For the validation data sets, PESTDRAIN was able to simulate accurately drainage discharge with Nash-Sutcliffe efficiency coefficients of 0.57 and 0.69 . The global $N_{\text {eff }}$ was 0.44 for all flow-weighted average weekly concentrations in drainage. Relative errors for the pesticide losses were $2.5 \%$ and $35 \%$ (IPU), and $60 \%$ (DFF). For surface runoff the results were not as accurate, but they remained correct in terms of time location and order of magnitude. Although further validation is
\end{abstract}

\footnotetext{
${ }^{*}$ Cemagref, UR HHLY, 3 bis quai Chauveau, CP 220 F-69336, Lyon Cedex 09, France

${ }^{\dagger}$ Cemagref, UR HBAN, Parc de Tourvoie, BP 44 F-92163, Antony Cedex, France

${ }^{\ddagger}$ Cemagref, UR QELY, 3 bis quai Chauveau, CP 220 F-69336, Lyon Cedex 09, France

$\S$ Cemagref, UR HBAN, Parc de Tourvoie, BP 44 F-92163, Antony Cedex, France

${ }^{\top}$ Cemagref, UR HHLY, 3 bis quai Chauveau, CP 220 F-69336, Lyon Cedex 09, France

"LTHE - UMR 5564 (CNRS, INPG, IRD, UJF) BP 53 F-38041, Grenoble Cedex 09,
} France 
necessary with more field data, PESTDRAIN appears as a promising tool for agricultural water management.

PESTDRAIN; Model; Subsurface drainage; Surface runoff; Pesticide

\section{Introduction}

Since the beginning of the 1990s, water quality concerns have grown in Europe, for both surface water and groundwater. Agricultural pesticide non-point source pollution has been identified as an important issue by the European Water Framework Directive (2000). Recent surveys show that in France $96 \%$ and $61 \%$ of sampling points in surface water and in groundwater, respectively are significantly contaminated by agricultural pesticides (IFEN, 2006). Many factors may influence the concentration levels at the outlet of a farmed catchment. Among them, subsurface drainage is a widely used agricultural management technique: it consists of perforated tiles buried into the soil which transfer excess water from subsurface to an outlet, typically a surface drainage ditch. In case of waterlogging, subsurface drainage improves soil bearing and facilitates crop growth by a better soil oxygenation.

It is now well-established that the presence of tile drains improves the soil infiltration capacities and therefore contributes to reduce surface runoff and the associated pesticide losses. However, surface runoff events can still be observed, due to soil saturation excess or soil surface crusting (Augeard et al., 2005). In the soil, fast water flow and pesticide transport to the drain are commonly observed, with high breakthrough concentrations attributed to preferential flow (Kladivko et al., 1991, 2001; Flury, 1996; Zehe and Flühler, 2001). The environmental impact is all the more important that tile drains usually discharge directly into the hydrographic network. Quantifying the pesticide transport from a tile-drained field is crucial to assess the environmental impact on surface water bodies. Numerical models are valuable tools for addressing this issue. They can help in defining adequate agricultural and water management practices. For that purpose, they must be able to predict the drainage and surface runoff flow rates and associated pesticide concentrations with enough accuracy. Not only average pesticide fluxes at daily or larger temporal scales are required, but also concentrations at the event scale, which are crucial for the assessment of acute contamination (Andersen et al., 2006; Boesten et al., 2007).

Several models are available that differ by their representations of the hydrological processes and their objectives. Among the models with management purposes, a first class of models gathers pesticide leaching 1D models that can also account for subsurface drainage through specific options, such as MACRO (Larsbo and Jarvis, 2003), PEARL (Leistra et al., 2001), LEACHP (Dust et al., 2000), RZWQM (Bakhsh et al., 2004) or AGRI- 
Paper published in Agricultural Water Management 96 (2009) 415-428

FLUX (Banton and Larocque, 1997). A second class of models regroups drainage-specific models, such as DRAINAGE (Kumar and Kanwar, 1997), ADAPT (Kalita et al., 1998), DRAINMOD/GLEAMS (Rudra et al., 2005) and PESTFATE (Bera et al., 2005), which are different combinations of the drainage engineering model DRAINMOD (Skaggs, 1999) and the pesticide leaching model GLEAMS (Leonard et al., 1995).

These models focus on the simulation of pesticide leaching in drainage. Although some of them might be able to simulate surface runoff, no tests on both surface runoff and drainage data were found in the literature. Moreover, most of these models use a daily time step allowing to simulate adequately average drainage rates and pesticide loading. This is not fully appropriate for the prediction of pesticide breakthroughs during rainfall events, which match rather hourly or sub-hourly temporal scales. Yet one of the major concerns about the existing approaches is that their validation status is quite low (Vanclooster et al., 2000; Dubus et al., 2002). This may be due to a lack of data, poor parameter identification techniques, or user subjectivity in the parameterization process, all the more that the models have complex structures and involve many parameters (Boesten, 2000; Dubus et al., 2003). A strategy to overcome this problem is to conceive more simplified models, and this approach has been addressed for a few years by the pesticide modelling community (Stewart and Loague, 1999; Tiktak et al., 2006). The PESTDRAIN model has been developed within this framework. The general objective is to obtain a simple, easy to use model able to simulate both surface runoff and tile-drainage flow rates, as well as the associated pesticide concentrations, in particular at the event temporal scale. The specific objective in this paper is to present the principles and structure of PESTDRAIN and to discuss a first evaluation of this model using experimental data.

\section{Model description}

PESTDRAIN consists of three modules, which are coupled together using a modelling framework named LIQUID (Viallet et al., 2006):

1. SIDRA is physically-based and simulates the water flow in the saturated zone.

2. SIRUP is capacity-based and simulates the water flow in the unsaturated zone and the surface runoff.

3. SILASOL is transfer function-based and simulates the pesticide transport in both the saturated and unsaturated zones.

SIDRA and SIRUP were developed from previously existing models, whereas SILASOL is a new development which will be described hereafter in more details. All the computations are made at the scale of a draining system 
Paper published in Agricultural Water Management 96 (2009) 415-428

(see Fig. 2), which is classically assumed to be representative of the whole drained field (Lesaffre and Zimmer, 1988). The input and output fluxes are computed per unit area.

\subsection{Water flow simulation: SIDRA and SIRUP}

\subsubsection{Drainage flow simulation: SIDRA}

SIDRA (SImulation of DRAinage) was originally developed with the objective of explaining and predicting fast peak drain flow rates that occur in winter during rainfall events in French shallow silty clay soils. As SIDRA is described in detail in Lesaffre and Zimmer (1988) and Zimmer et al. (1995), only a short summary is provided here.

SIDRA is based on the classical approach of the Boussinesq equation for the saturated zone. The Boussinesq equation is integrated analytically, assuming vertical equipotential lines (Dupuit-Forchheimer assumption) and a constant elliptic water table shape. It leads to the following equations:

$$
\begin{gathered}
\mu A_{2} \frac{d H}{d t}=\Phi(t)-J(H) \\
Q(t)=A_{1} J(H)+\left(1-A_{1}\right) \Phi(t) \\
J(H)=\frac{K H^{2}}{L^{2}}
\end{gathered}
$$

where $H(t)$ is the water table elevation at midway between two parallel drains $[L] ; Q(t)$ the drain flow rate $\left[L T^{-1}\right] ; A_{1}$ and $A_{2}$ are constant water table shape factors [-]. Assuming an elliptic water table, their theoretical values are 0.86 and 0.90, respectively (Lesaffre and Zimmer, 1988). $\mu$ is the drainable porosity $[-] ; \Phi(t)$ is the recharge rate $\left[L T^{-1}\right]$ and $J(H)$ is the Hooghoudt function (Hooghoudt, 1940), corresponding to the steady-state solution of the Boussinesq equation. $L$ is the half drain spacing $[L] . K$ is the soil equivalent saturated hydraulic conductivity $\left[L T^{-1}\right]$. In the SIDRA module, Eqs. 1 and 2 are solved numerically using the Euler algorithm.

The first right-hand term of Eq. 2 represents the water table contribution to drainage flow. The second term is independent from water table rise and corresponds to the contribution of recharge. It is responsible for peak flow (Bouarfa and Zimmer, 2000). In comparison with models using only the Hooghoudt steady-state equation such as DRAINMOD (Skaggs, 1999), this recharge contribution term allows SIDRA to simulate fast peak flows without additional fast flow component. SIDRA was successfully applied to several field data sets in France and northern Africa (Lesaffre and Zimmer, 1988; Zimmer et al., 1995; Giraud et al., 1997; Hartani et al., 2003). 


\subsubsection{Surface runoff simulation: SIRUP}

A major limitation of SIDRA is that it is unable to predict surface runoff. SIRUP (SImulation of RUnoff at the Plot scale) was developed for this purpose (Kao et al., 1998). It allows to compute surface runoff and recharge to the water table as functions of the rainfall, the potential evapotranspiration (PET) and the water table level. SIRUP consists of three separate conceptual reservoirs, respectively accounting for (Fig. 1):

- Storage of water in the superficial soil layer, and infiltration/runoff distribution depending on the water table depth (Reservoir 1 with 3 parameters)

- Storage of infiltrated water and moisture distribution in deeper soil layers, evapotranspiration and recharge to the water table (Reservoir 2 with 1 parameter)

- Lamination of surface runoff (Reservoir 3 with 1 parameter)

Reservoir 1 has a maximum water level $R 1[L]$ and stores rainfall water. Water flows from reservoir 1 to 2 according to the emptying equation:

$$
\varphi_{1}(t)=l_{1}(t)[T(d-H(t))+M]
$$

where $\varphi_{1}\left[L T^{-1}\right]$ is the emptying flow, $d[L]$ is the depth of the impervious layer, $l_{1}(t)[L]$ is the water level in Reservoir $1, \mathrm{~T}\left[L^{-1} T^{-1}\right]$ and $\mathrm{M}\left[T^{-1}\right]$ are empirical parameters. Eq. 4 accounts very simply for the influence of the water table level on soil infiltration: a high water table level implies a reduced infiltration flow. When Reservoir 1 overflows, excess water flows to Reservoir 3 and is changed into surface runoff, according to:

$$
\varphi_{3}(t)=l_{3}(t) B
$$

where $\varphi_{3}\left[L T^{-1}\right]$ is the emptying flow of Reservoir $3, l_{3}(t)[L]$ is the water level and $\mathrm{B}\left[T^{-1}\right]$ is an empirical parameter. Reservoir 2 , at last, receives infiltration flow from Reservoir 1 and is emptied by evapotranspiration only. It has a maximum water level $R 2[L]$. The overflowing water constitutes the recharge to the water table $\Phi(t)$ (see Eqs. 1 and 2).

SIRUP was tested by Kao et al. (1998) on data of drained and undrained plots from the La Jaillière experimental site.

\subsection{Solute transport simulation: SILASOL}

\subsubsection{Principles}

Solute transport simulation in the PESTDRAIN model uses a conceptualization based on the experimental observations of water flow paths in 
Paper published in Agricultural Water Management 96 (2009) 415-428

2D subsurface drainage systems by Arlot (1999) and Paris (2004). The study involved field observations, tracer experiments with a physical model and numerical simulations with the physically-based comprehensive model HYDRUS-2D (Simunek et al., 1999). It showed that the water velocity field in the soil profile is sharply contrasted: close to the drain, high hydraulic gradients generate fast radial flow in both saturated and unsaturated zones, whereas velocities are very low at mid drain. As an example, Fig. 2 represents streamlines in a tile-drained soil profile for a pulse of solute imposed as boundary condition at the soil surface. It shows that not only travel distances, but also travel times are much lower close to the drain. This may be related to the differentiation of water flow that is made in SIDRA (Zimmer, 2001). In the low velocity zone, solute migrates through the water table; this zone corresponds to the contribution of the water table to drain flow and solute transport according to Eq. 2. On the other hand, the high velocity zone corresponds to the contribution of recharge with solute direct migration to the drain. The SILASOL module formalizes this analysis of physical processes in a simple manner. The soil is conceptually divided in two compartments, as shown in Fig. 3. Compartment 1 represents the soil located far from the drain, corresponding to low velocities and the contribution of the water table to solute transport. Compartment 2 represents the soil located close to the drain, corresponding to high velocities and the contribution of recharge. A characteristic solute transfer time and a contribution to the total drain concentration are attributed to each compartment.

Solute transport is simulated in each compartment using a transfer function. The interest of transfer functions for simplified modelling approaches is that they allow to characterize a system output without representing explicitly the internal processes (Jury, 1982). They do not involve any complex numerical solution and require a limited number of parameters. Many examples of the application of transfer functions to drainage are reported in the literature (e.g. Van Ommen, 1985a,b; Van Ommen et al., 1989; Vinten et al., 1991; Scotter et al., 1993; Magesan et al., 1994; White et al., 1998). However such applications involve only one transfer function for the whole soil. The originality of the SILASOL approach is to use two parallel transfer functions - one for each compartment.

\subsubsection{Transfer function for each compartment}

The general steady-state form of the transfer function equation for a nonreactive solute is given by Jury and Roth (1990):

$$
C_{\text {out }}(I)=\int_{-\infty}^{I} C_{\text {in }}\left(I-I^{\prime}\right) f\left(I^{\prime}\right) d I^{\prime}
$$

where $C_{\text {in }}$ and $C_{\text {out }}$ are the input and output concentrations $\left[M L^{-3}\right]$ of the modelled system, respectively, $I$ is the cumulative drainage flow $[L]$, and $f(I)$ 
is the probability density function (pdf) for solute travel through the soil. The pdf is defined as the normalized outflow concentration corresponding to an input pulse of solute. The exponential pdf is considered as the most appropriate for soils with shallow subsurface drains (Magesan et al., 1994; White et al., 1998). It derives from a simplified analysis of flow patterns to subsurface drains (see for example Van Ommen, 1985b). The equation for this pdf writes:

$$
f(I)=\frac{1}{a} \exp (-I / a)
$$

where $a$ is the only parameter $[L]$, equal to the effective solute transport volume per unit area.

Flow to subsurface drains is generally transient rather than steady during natural rainfall events. However, according to Jury and Roth (1990), Eqs. 6 and 7 may remain adequate, provided that the variations of the soil solute transport characteristics (in particular water content) are limited and the time steps are appropriately small. Doing so, the transient conditions are represented by a succession of steady states $(\Delta I=Q(t) \times \Delta t$ where $Q(t)$ is the drain flow rate $\left[L T^{-1}\right]$ and remains constant within a time step $\Delta t)$. In the case of shallow soils during the winter drainage season, the water table level remains high and the soil moisture close to saturation, even though the flow is not steady (Lesaffre and Zimmer, 1988; Arlot, 1999). The specification of the model time step is discussed in more details in Sec. 2.3. We consider that PESTDRAIN irregular time steps are small enough to be compatible with the assumption of successive steady states during rainfall events.

For the adsorption of pesticides on soil particles, a linear isotherm with instantaneous equilibrium between solid and liquid concentrations was selected as the simplest representation. It is taken into account in the transfer function by the following variable change (Jury and Roth, 1990; Heng et al., 1994):

$$
f_{\text {adsorption }}(I)=\frac{1}{R} f\left(\frac{I}{R}\right)
$$

$R$ is the retardation factor [-], defined as:

$$
R=1+\frac{\rho_{d} K_{d}}{\theta}
$$

where $K_{d}$ is the soil-water partition coefficient $\left[L^{3} M^{-1}\right], \rho_{d}$ is the soil dry bulk density $\left[M L^{-3}\right]$ and $\theta$ is the soil volumetric water content $\left[L^{3} L^{-3}\right]$. Degradation is usually described by first-order kinetics. A decreasing exponential factor is therefore added to the pdf (Jury and Roth, 1990):

$$
f_{\text {degradation }}(I)=\exp (-\lambda I / Q) f(I)
$$

where $\lambda\left[T^{-1}\right]$ is the first-order decay coefficient of the chemical compound. $\lambda$ is related to the half-life DT50 according to: $\lambda=\ln 2 / D T 50$. 


\subsubsection{Assembling of the compartments}

Each compartment $i$ is characterized by a specific value for the exponential pdf parameter $a_{i}$ and a relative contribution to drain flow $c_{i}[-]$. According to the principles of the SILASOL module, these contributions are related to the water table shape factor $A_{1}$ of the SIDRA module (Eq. 2). This implies two assumptions: first, the relative contributions of the compartments to drain flow are supposed to be constant; second, we assume no interaction between the two compartments during transport and a perfect mixing of the two solute compartment outputs directly in (or at the vicinity of) the drainage pipe. This leads to a global output of the draining system given by:

$$
C_{\text {out }}=C_{\text {out }}^{1} c_{1}+C_{\text {out }}^{2} c_{2}
$$

with $c_{1}=A_{1}$ (slow transport compartment) and $c_{2}=1-A_{1}$ (fast transport compartment).

\subsubsection{Computation of the input and surface runoff concentrations}

The SILASOL module also includes a solute surface storage (Fig. 3). It corresponds to a superficial layer of soil in which the chemical compound is incorporated at pesticide application. A solute mass balance, performed in this surface storage, allows to calculate the input concentration for the transfer functions as well as the concentration in surface runoff water. We assume that the pesticide application at the soil surface is homogeneous. As a consequence, the input concentration is the same for both compartments.

The solute concentration in the surface runoff flow $C_{\text {runoff }}\left[M L^{-3}\right]$ and the input concentration for the transfer functions $C_{i n}\left[M L^{-3}\right]$ are deduced from solute washout flows. These washout flows $\left(F_{r}\right.$ for surface runoff and $F_{i}$ for transfer function input) are calculated as follows:

$$
F_{r}=\frac{m_{L}}{w_{c}} \phi_{r} \quad \text { and } \quad F_{i}=\frac{m_{L}}{w_{c}} \max \left(\phi_{\text {rain }}-\phi_{r}, 0\right)
$$

where $\phi_{\text {rain }}$ is the rainfall $\left[L T^{-1}\right]$ and $\phi_{r}$ is the surface runoff water flow per unit area $\left[L T^{-1}\right]$ computed by the SIRUP module. $m_{L}\left[M L^{-2}\right]$ is the amount of pesticide in the liquid phase of the surface storage, considered as the only available for washout; $w_{c}[L]$ is the water capacity characterizing the surface storage. It represents the unitary volume of water in which the solute is dissolved.

For a given time step $\Delta t, m_{L}$ is estimated assuming perfect mixing in the surface storage, linear adsorption with instantaneous equilibrium and first-order decay kinetics:

$$
m_{L}=\frac{m_{T}}{R} \exp (-\lambda \Delta t)
$$


where $R$ is given by Eq. 9, $\lambda$ is given by Eq. 10, and $m_{T}$ is the applied amount of pesticide per unit area $\left[M L^{-2}\right]$. Pesticide volatilization is neglected as well as uptake by plants.

\subsection{Module coupling through the LIQUID modelling frame- work}

SIDRA, SIRUP and SILASOL were implemented within the LIQUID environmental modelling framework (Viallet et al., 2006), which provides templates for module structure and programming. The LIQUID platform also performs the coupling between modules and carries on simulations. Fig. 4 shows the structure of the PESTDRAIN model and the variables exchanged by the three component modules. SIDRA and SIRUP are coupled bidirectionnally: SIRUP needs the water table level provided by SIDRA to compute the recharge, which is used by SIDRA for computing the water table level (see Eqs. 1 and 4). SIDRA and SIRUP provide SILASOL with drain flow rate and surface runoff rate, respectively but without any feedback (one-way coupling).

The LIQUID modelling framework has a specific way of handling simulation progression in time. Each module of a model is considered as an autonomous entity with its own inputs and outputs, and is able to estimate a priori at each of its time steps its own following time step. This estimation is made according to numerical or physical criteria that are implemented by the module developer. Whenever an unexpected event occurs such as a change in one of the module's inputs, the module has the ability to interrupt the computation and to shorten its time step in order to take into account the new input value immediately. This approach leads to simulations with irregular time steps. This enables an efficient coupling between the several modules and a good model accuracy during transient periods, without losing any computational time during steady periods. In PESTDRAIN, the time step is governed by the external forcings and the internal states of SIDRA, SIRUP and SILASOL. Basically, the mechanism for PESTDRAIN is the following:

- A new time step is computed in SIRUP each time rainfall or PET change. An additional rule sets that the level in each reservoir of SIRUP should not increase or decrease by more than $5 \%$ in a single time step.

- A new time step is computed in SIDRA each time recharge (from SIRUP) changes. An additional rule sets that the water table level should not increase or decrease by more than $5 \%$ in a single time step.

- A new time step is computed in SILASOL each time rainfall, surface runoff (from SIRUP) or drain flow rate (from SIDRA) change. A new 
time step is also forced at each pesticide application. An additional rule specifies that no more than $20 \%$ of the available solute quantity should be washed off during a single time step.

Full details can be found in Branger et al. (2006) and Branger (2007). As a result, intense rainfall events generate important variations of the levels in both the SIRUP reservoirs and the water table, thus leading to reduced time steps. The effective time step of PESTDRAIN is therefore very short (3 minutes or less, also depending on the model parameterization). This allows accurate simulations of drainage and surface runoff events. It also validates the assumption of successive steady states that is made for the SILASOL transfer functions.

\section{Model application}

\subsection{Experimental site}

Data used for evaluating PESTDRAIN were collected at the experimental site of La Jaillière, run by the technical institute Arvalis - Institut du Végétal. It is located in western France, at the southern end of the Armorican massif. The site has been dedicated to the study of the influence of agricultural management practices on water quality since 1993, and is a reference site for the European Commission FOCUS working group (FOCUS, 2001). This working group coordinates the use of pesticide leaching models or indicators for the estimation of predicted environmental concentrations (PECs) in the pesticide registration and evaluation procedures. The La Jaillière site is considered as representative of the agricultural regions in Europe with shallow silty clay soils.

Soils are hydromorphic brown with a silty clayed texture, and a shallow schistose bedrock situated at about $0.90 \mathrm{~m}$ below the surface. The average clay content is $22 \%$ (Madrigal, 2004), but variations from $18 \%$ to $30 \%$ were observed depending on the soil horizons (Arlot, 1999). Organic matter content was found to be in average $2 \%$ in the superficial soil horizon (Madrigal, 2004). The climate is of oceanic type with a mean annual precipitation of $617 \mathrm{~mm}$ evenly distributed along the year (monthly values between 40 and $62 \mathrm{~mm}$ ), and a mean annual potential evapotranspiration of $610 \mathrm{~mm}$.

The studied 1-ha plot is cultivated following a traditional winter wheat/corn crop rotation. It is equipped with an independent tile drainage system and surrounded by gravelled cuttings for hydraulic isolation from the other farm fields and with a collecting gutter for surface runoff measurement as well. Tile drains are located at $d=0.9 \mathrm{~m}$ below the soil surface, with a spacing $2 L=10 \mathrm{~m}$. They lie on the impervious bedrock. The estimated equivalent horizontal saturated hydraulic conductivity is $K=0.5 \mathrm{~m} \cdot \mathrm{day}^{-1}$ and drainable porosity values range from $3 \%$ to $6 \%$. The estimated average 
soil dry bulk density is $\rho_{d}=1.35 \mathrm{~g} . \mathrm{cm}^{-3}$ and the average soil porosity is $0.38 \mathrm{~m}^{3} \cdot \mathrm{m}^{-3}$ (Arlot, 1999).

Rainfall and potential evapotranspiration (PET) are available at the site, with an hourly time step for rainfall and a daily time step for PET. Subsurface drainage and surface runoff rates are routinely monitored at an hourly time step. All agricultural operations (ploughing, fertilization, pesticide treatments) are reported in a data base by Arvalis. It includes notably pesticide application date and time, chemical molecules, product formulation and applied quantities. Measurements of pesticide are made in samples of drainage and runoff waters and these measurements are given as flow-weighted, average weekly concentrations. A 2-week intensive campaign was additionally conducted in December 2003 with pesticide sampling every 3 hours.

The studied pesticides are the wheat herbicides isoproturon (IPU) and diflufenican (DFF). They are applied together in flowable concentrate at rates of $1 \mathrm{~kg} \cdot h \mathrm{a}^{-1}$ and $0.125 \mathrm{~kg} \cdot \mathrm{ha^{-1 }}$, respectively. The main physical and chemical properties of both herbicides are summarized in Table 1. Data were taken from the online database AGRITOX ${ }^{1}$, and from laboratory studies which were conducted on undisturbed soil samples collected at different horizons in the first $60 \mathrm{~cm}$ of the soil (Madrigal et al., 2002; Madrigal, 2004). Isoproturon is quite a mobile molecule with moderate sorption properties and is not very persistent. On the opposite, diflufenican has a low solubility, a high sorption potential, and a long persistence. The leachability of these two pesticides can be characterized using the Groundwater Ubiquity Score (GUS) index (Gustafson, 1989), given by:

$$
\operatorname{GUS}=\left(4-\log K_{o c}\right) \times \log (D T 50)
$$

Following Gustafson (1989), a pesticide presents a high leaching potential for a GUS higher than 1.8. The GUS values for IPU and DFF reported in Table 1 were estimated by average values for sorption coefficient $K_{o c}$ and half-life given in the AGRITOX database. They show that isoproturon presents a higher leaching risk and is therefore more likely to be found in drainage water with high concentrations than diflufenican.

\subsection{Main drainage and solute transport patterns}

Drainage data from the La Jaillière experimental site were previously studied by Arlot (1999) and Carluer and Tournebize (2006). The drainage season (during which tile-drainage is active) usually starts in November and ends in March. The mean annual cumulative drainage discharge over a season is about $220 \mathrm{~mm}$ (1986-2004). Drainage is very reactive to rainfall events, with response time of less than $1 \mathrm{~h}$ and peak flow intensities up to $1.5 \mathrm{~mm} . \mathrm{h}^{-1}$. It

\footnotetext{
${ }^{1}$ http://www.dive.afssa.fr/agritox/index.php
} 
Paper published in Agricultural Water Management 96 (2009) 415-428

is noteworthy that these intensities are quite high in comparison with other studies reported in the literature (Abbaspour et al., 2001; Beulke et al., 2001; Gärdenäs et al., 2006; Tiemeyer et al., 2007). The analysis of the pesticide concentration data by Carluer and Tournebize (2006) showed that high isoproturon concentrations are generally exported during the first drainage events following pesticide applications. Then the concentrations decrease quite fast. This suggests that IPU leaches from the superficial layers of soil to the drain without necessarily migrating through the water table. Diflufenican appears to be less sensitive to the hydrodynamical conditions. However these general trends are subject to high variability, in particular according to the climatic conditions. It is therefore difficult to identify thoroughly the involved processes.

\subsection{Model calibration and validation}

For all simulations, the model was fed directly with the rainfall measurements at an hourly time step. The potential evapotranspiration values were disagreggated to an hourly time step by distributing uniformly each daily value over the daytime (from 7 am to $7 \mathrm{pm}$ ).

We chose the 2003-2004 season as the calibration period for PESTDRAIN. This season is representative of the average behaviour of the experimental site. The calibration was performed manually in two steps: the water flow modules SIDRA and SIRUP were calibrated first on the whole season data set; the solute transport module SILASOL was then calibrated using the high temporal resolution IPU concentration data acquired in December 2003. The calibration of SILASOL was also performed in two steps:

1. calibration of the pesticide surface storage on the surface runoff measurements

2. calibration of the transfer functions according to the measured concentrations in drainage discharge

Not all of the 16 parameters of PESTDRAIN were calibrated (see Table 2). In SIDRA, only the drainable porosity was calibrated. The saturated hydraulic conductivity was set according to the available field value and the water table shape factors $A_{1}$ and $A_{2}$ according to their theoretical values. In the fully conceptual SIRUP, all five parameters were estimated through calibration, using as a basis the parameter set previously found by Kao et al. (1998) on the same experimental site. In SILASOL, only the water capacity $w_{c}$ and the transfer function parameters $a_{1}$ and $a_{2}$ were calibrated. The relative contributions of the two compartments $c_{1}$ and $c_{2}$ were not calibrated and were imposed at their theoretical values according to Eq. 11 . The pesticide parameters $\lambda$ and $R$ were also used without calibration. The values of the degradation coefficient $\lambda$ were set using the average of half-lives from the 
AGRITOX database in Table 1. The retardation factors $R$ were estimated by Eq. 9 using the available field and literature data. We supposed that the soil volumetric water content $\theta$ was constant and equal to the soil average porosity, consistently with the assumption of soil quasi-saturation made for the transfer functions in section 2. All the parameter values are given in Table 2.

After calibration, the model was evaluated on independent data sets for the drainage seasons 1995-1996 and 1999-2000. The 1999-2000 season is a regular season, whereas the 1995-1996 is particularly dry with a cumulative rainfall of only $167 \mathrm{~mm}$, and a cumulative drainage of $106 \mathrm{~mm}$. The validation data sets for pesticide transport consist of flow-weighted, average weekly concentrations for IPU and DFF for the 1995-1996 season and IPU only for the 1999-2000 season. Unfortunately, no other data set with a high temporal resolution was available.

The model performance at both calibration and evaluation was assessed visually by graphical displays or by using quantitative criteria. The global ability of the model to reproduce cumulative values over the whole season was estimated through the relative error on cumulative volumes or pesticide exported quantities:

$$
\text { Err }=\frac{\left|\mathrm{Cum}_{\mathrm{obs}}-\mathrm{Cum}_{\text {sim }}\right|}{\mathrm{Cum}_{\mathrm{obs}}} \times 100
$$

where Cum is the considered cumulative variable (water volume or pesticide quantity).

For non-intermittent variables, such as drainage discharge and associated pesticide concentrations or flows, the Nash-Sutcliffe efficiency coefficient was used (Nash and Sutcliffe, 1970):

$$
N_{\text {eff }}=1-\frac{\sum\left(Q_{\mathrm{obs}}-Q_{\mathrm{sim}}\right)^{2}}{\sum\left(Q_{\mathrm{obs}}-\overline{Q_{\mathrm{sim}}}\right)^{2}}
$$

For surface runoff water flow and associated pesticide transport, more qualitative criteria were used, such as the temporal location and the order of magnitude of surface runoff and concentration peaks, mainly because no quantitative criteria are adapted for such intermittent processes.

\section{Results and discussion}

\subsection{Calibration}

\subsubsection{Water flow}

Fig. 5 shows the calibration results for the water flow modules SIDRA and SIRUP. The corresponding parameter set is given in Table 2. For drainage discharge (Fig. 5a), the error on the cumulative volume over the 
whole period is $+14 \%$, and the value of the Nash-Sutcliffe efficiency coefficient is $N_{\text {eff }}=0.58$, which is very acceptable. The model also reproduces well the drainage dynamics. However, the highest drainage peaks (above $0.7 \mathrm{~mm} . \mathrm{h}^{-1}$ ) are systematically underestimated. The model also overestimates the drainage discharge at the beginning of the simulation period. Yet this may be explained by the particular conditions of the experimental site: Arlot (1999) reports the presence of a deeper aquifer that influences the perched water table during drainage start. For surface runoff (Fig. 5b), the model was able to reproduce six of the eight observed events in terms of time locations and orders of magnitude. The cumulative flow is very well simulated, with an error of $+4 \%$. Unlike subsurface drainage, surface runoff is an intermittent process; it is more difficult to simulate precisely over long periods. Therefore, although two of the eight runoff peaks were missed and some values underestimated, we can consider the model calibration results as very satisfactory.

Additional investigations were conducted in order to explain the model limitations for the simulation of drainage discharge. The analysis of the underestimation of the maximal drainage peaks showed that the SIRUP unsaturated zone module does not provide the SIDRA saturated zone module with a sufficient recharge for high water table levels. The calibration of SIRUP could not correct the problem without damaging the simulation of surface runoff. We managed to compensate it partly using a very low value of the drainable porosity in SIDRA $(\mu=0.01$, see Table 2$)$, which makes the water table extremely reactive to recharge variations. Still this low parameter value is not consistent with the field estimation made by Arlot (1999) and causes side-effects such as excessive recessions after drainage peaks. Solutions for the improvement of the model performances would be to modify the dependence on the water table level in the emptying law of SIRUP's Reservoir 1 (Eq. 4) or to add in the SIDRA equations (Eqs. 1 and 2) a term accounting for the deformation of the water table (Bouarfa and Zimmer, 2000). These options are currently being tested.

\subsubsection{Pesticide transport}

Fig. 6 shows the model calibration results for pesticide transport. The key parameter for the simulation of surface runoff concentrations in the solute transport module SILASOL is the water capacity $w_{c}$ (see Eq. 12). Considering a thickness of $0.05 \mathrm{~m}$ for the surface storage and the average fieldestimated porosity value of $0.38, w_{c}$ was initially set at $0.02 \mathrm{~m}$. But this value led to unacceptably overestimated simulated concentrations. Fig. 6a shows that no physically consistent value (corresponding to a soil layer thickness with an acceptable order of magnitude) allowed to reproduce accurately the measured concentrations. As a compromise, the value of $0.15 \mathrm{~m}$ was selected (see Table 2). It is the lowest value of $w_{c}$ (corresponding to a soil 
layer thickness of $0.39 \mathrm{~m}$ ) that allows to simulate concentration levels with an acceptable order of magnitude (below $100 \mu \mathrm{g} / \mathrm{L}$ ). This indicates that $w_{c}$ may be actually a lumped parameter in the present version of the model. However, as $w_{c}$ remains within a reasonable order of magnitude $(0.1 \mathrm{~m})$ it is probably not completely disconnected from any physical meaning. Additional tests and sensitivity analyses are required to characterize more precisely this parameter, to provide ranges of values and to correlate them with the available field data.

On the other hand, the calibration of the transfer function parameters in SILASOL leads to a remarkably good fit between simulated and measured IPU concentrations in drainage (Fig.6b). The alternation of high peak and low recession concentrations, as well the values of these concentrations are reproduced with accuracy. The efficiency coefficient for this calibration is $N_{\text {eff }}=0.28$, which can be considered as satisfying for pesticide transport. The corresponding parameter values are $a_{1}=0.2 \mathrm{~m}$ and $a_{2}=1.0 \times 10^{-4} \mathrm{~m}$ for slow and fast transport compartments, respectively. The analysis of the contribution of the compartments (not shown) indicates that the fast transport compartment is responsible for the high concentration peaks and their dynamics, whereas the slow transport compartment does not contribute significantly to pesticide losses and has mainly a dilution effect. This is consistent with the interpretation made by Carluer and Tournebize (2006) about the IPU leaching mechanism, all the more that pesticide application occurred only a few days before the simulation period. This validates the conceptualization that is made in SILASOL with the choice of two independent compartments. In particular, the interpretation of slow and fast transport in terms of water table and recharge contributions appears to be relevant.

The orders of magnitude of $a_{1}$ and $a_{2}$ values are consistent with our expectations: when interpreting $a_{i}$ as the soil unitary pore volume that is involved in solute transport (excluding soil sorption, which is taken into account separately by the retardation factor $\mathrm{R}$ ), its values should not exceed the total soil unitary pore volume, that is equal to $0.38 \times 0.9=0.34 \mathrm{~m}$. Both values of $a_{1}$ and $a_{2}$ are in adequacy with this assumption. Values that can be found in the literature for the exponential transfer function parameter (considering only one compartment) range from $0.1 \mathrm{~mm}$ (Vinten et al, 1991) to more generally 100 - $150 \mathrm{~mm}$ (Scotter et al., 1991; Magesan et al., 1994; White et al., 1998). This also indicates that the values for $a_{1}$ and $a_{2}$ are quite reasonable, although the transposition of literature results to our twocompartment case might be delicate. Yet, like the water capacity $w_{c}$, the transfer function parameters $a_{1}$ and $a_{2}$ are rather conceptual. Additional tests should be undertaken in order to characterize them more precisely and link them to field data.

In order to further analyze the calibration results, the influence of the performances of the water flow modules SIDRA and SIRUP on the calibrated 
Paper published in Agricultural Water Management 96 (2009) 415-428

values of SILASOL parameters was studied. This is particularly important for drainage discharge because the calibration period of SILASOL is precisely the beginning of the drainage season, which is not simulated very accurately by the model (Fig. 5a). Fig. 7 shows the results of exploratory standalone simulations conducted with the SILASOL module (made possible by the modular structure of PESTDRAIN). In these simulations, the simulated surface runoff (Fig. 7a) or the simulated drainage discharge (Fig. 7b) were replaced by the measured data (otherwise using exactly the same inputs and parameterizations as in the calibration). Surface runoff flow was quite well simulated by PESTDRAIN during the calibration period of SILASOL. Nevertheless, Fig. 7a shows that the slight differences between simulation and measurement induce large discrepancies in the IPU simulated concentrations. A different value for the soil water capacity $w_{c}$ would be required to match the measurements according to the above criteria. This may reveal some compensation mechanism for pesticide concentrations in surface runoff. On the other hand, the calibrated values for the transfer function parameters $a_{1}$ and $a_{2}$ seem adequate even when using the measured drainage discharge instead of the simulation (Fig. 7b). This indicates that there is no compensation effects for pesticide concentrations in drainage.

\subsection{Validation}

\subsubsection{Water flow}

The validation results for water flow are presented in Table 3 . For drainage discharge, the errors on the cumulative volume over the whole simulation periods are $6 \%$ and $8.5 \%$ for the 1995-1996 and the 1999-2000 seasons, respectively. The Nash-Sutcliffe efficiency coefficient values are 0.57 and 0.69 . They show that the model is able to reproduce the measured discharge with accuracy. The details of the simulations (not shown) are similar to those presented in Fig. 5 for calibration. In particular, the model limitations are the same: drainage discharge is overestimated at the beginning of the simulation periods, and some of the maximum peaks are underestimated. The analysis that was made after calibration is therefore confirmed.

For surface runoff, the results are not as accurate as for calibration. The quantitative values of surface runoff volumes are considerably overestimated by the model. The errors on the cumulative volume over the whole simulation periods are $125 \%$ and $24 \%$ for the 1995-1996 and the 1999-2000 seasons, respectively. However the model remains able to reproduce the general dynamics of flow generation. This can be observed in the abscisses of Fig. 10, which represent the cumulative surface runoff flow with one value per week: no surface runoff event (corresponding to a high cumulative volume within a week) is completely missed. A more precise analysis of the surface runoff hydrographs (not displayed here) shows that $50 \%$ of the sur- 
Paper published in Agricultural Water Management 96 (2009) 415-428

face runoff peaks are correctly located in time for the 1995-1996 season, and $80 \%$ for the 1999-2000 season. The discrepancies in the quantitative values of runoff volumes are due to the overestimation of one or two important peaks, at the end of the simulation periods (visible on Fig. 10).

\subsubsection{Pesticide transport}

The PESTDRAIN validation results for pesticide transport are synthetically presented in Fig. 8. The model performance appears to be very satisfactory for pesticide weekly averaged concentrations with a global Nash efficiency coefficient of 0.44 , although the model underestimates the highest concentration values. For surface runoff, the results are poorer but remain correct for low concentrations. As the weekly average concentrations are representative of the pesticide fluxes, Figs. 9 and 10, which present, respectively the cumulative weekly averaged pesticide loading in drainage and surface runoff as function of the cumulative water flow, allow a more precise interpretation of the validation results.

PESTDRAIN succeeds in simulating the IPU losses in drainage, in particular for the 1995-1996 season (Fig. 9a). The error on the cumulative pesticide flux over this season is only $2.5 \%$. The dynamics of pesticide loading and their dependence on drainage events are also reproduced particularly well, as states a Nash efficiency coefficient of 0.65. The model predictions are less accurate for the 1999-2000 season (Fig. 9b), with a relative error of $35 \%$ for total cumulative flow, which is mostly due to a single event occuring shortly after drainage start. Yet with a Nash efficiency coefficient of 0.37, we consider the model performance as very acceptable, as compared to the values for pesticide simulation that can be found in the literature (Dust et al., 2000; Scorza Jr. et al., 2007).

On the other hand, the model performance for simulating DFF flux lacks accuracy. The order of magnitude of DFF losses is acceptable, with a global error of $60 \%$ (Fig. 9a). But an efficiency coefficient of -0.2 indicates that the model predictions are poorer in terms of dynamics. This could be due to an inadequate value of the retardation factor $R$, which was set according to literature data and was not calibrated.

Fig 10 shows the pesticide transport results for surface runoff. The predicted pesticide loading appears to be widely overestimated, with global errors of $560 \%$ and $150 \%$ for IPU (1995-1996 and 1999-2000 seasons respectively) and $174 \%$ for DFF. The simulation of pesticide flux in surface runoff is strongly correlated to the simulation of water flow: for both seasons and pesticide molecules, the overestimated water flow events are also the overestimated pesticide loading events. This is consistent with the calibration results, that revealed an overestimation of pesticide concentrations in runoff through the calibrated value of the water capacity $w_{c}$ and a high sensitivity of these concentrations to the prediction of water flow. 


\section{Conclusions}

In order to assess the influence of subsurface drainage on pesticide leaching at the field scale, a simplified model named PESTDRAIN was developed and tested. PESTDRAIN is mainly based on the physically-based Boussinesq equation for drainage water flow and a conceptual transfer function approach for pesticide transport. It was developed within a modelling framework named LIQUID and it allows to simulate surface runoff flow and tile-drainage discharge, along with the associated pesticide concentrations, with a variable, event-driven time step.

The model tests were conducted with field data collected at the La Jaillière experimental site, and involved a calibration and an evaluation on independent data sets. The results show that the model is able to simulate quite satisfactorily water flow and solute transport in subsurface drainage. The dynamics of pesticide transport are well reproduced. This indicates that the representations of the drainage processes in the model are relevant. In particular, the use of an exponential transfer function for solute transport and the separation of fast and slow transport allow to reproduce the alternation of high breakthrough and low recession pesticide concentrations with a limited number of parameters. The very simple options that were taken for representing pesticide degradation and adsorption also appear to be justified. For surface runoff, the model performances are less accurate, although they remain correct in terms of time locations and orders of magnitude. They can be partly attributed to the natural difficulty for simulating this intermittent process. Yet the lumped value for the water capacity parameter that was obtained after calibration, and the fact that this parameter is strongly influenced by the performances of the water flow modules, indicate that the process representation that was chosen for the surface storage of SILASOL might be questioned.

At this stage, we can conclude that PESTDRAIN is a promising tool. In order to extrapolate the site-specific results presented in this paper, and assess the predicting abilities of PESTDRAIN, further validation must be undertaken. Tests on additional data sets for a broader spectrum of conditions (climate, soil type, pesticide molecules), and parameter sensitivity analyses should allow to characterize more precisely the parameters and to precise for which context the model is able to reproduce the water flow dynamics and pesticide transport and for which it is not.

\section{Acknowledgements}

This work was supported by the Cemagref in Lyon and Antony. The authors are very grateful to S. Debionne and P. Viallet at Hydrowide for making the LIQUID framework available and to D. de Sesmaisons for helping per- 
forming the simulations. Arvalis is acknowledged for providing field data. Chemical analyses were performed at INRA/Versailles and GIRPA/Angers laboratories.

\section{List of symbols}

\begin{tabular}{ll}
\hline$a\left(a_{i}\right)[L]$ & parameter of the exponential transfer function (for soil compart- \\
$A_{1}, A_{2}[-]$ & ment i) \\
$B\left[T^{-1}\right]$ & water table shape factors \\
$c_{i}[-]$ & parameter of the SIRUP R3 reservoir \\
$C_{\text {in }}, C_{\text {out }}\left[M L^{-3}\right]$ & relative contribution of the soil compartment i to drainage flow \\
$C_{\text {runoff }}\left[M L^{-3}\right]$ & input and output solute concentrations of the transfer functions \\
$d[L]$ & solute concentration in surface runoff \\
& depth of the soil impermeable layer assumed to be equal to drain \\
DT50 $[T]$ & depth \\
$F_{i}, F_{r}\left[M L^{-2} T^{-1}\right]$ & pesticide half-life \\
$H[L]$ & infiltration and surface runoff solute washout flows \\
$I[L]$ & water table level above impermeable layer at mid-drain spacing \\
$J$ & cumulative recharge \\
$K\left[L T^{-1}\right]$ & Hooghoudt steady-state function for subsurface drainage \\
$K_{o c}, K_{d}\left[L^{3} M^{-1}\right]$ & saturated hydraulic conductivity \\
$l_{1}, l_{2}, l_{3}[L]$ & pesticide soil-water partition coefficients (adsorption) \\
$L[L]$ & water levels in the SIRUP reservoirs R1, R2, R3 respectively \\
$m_{L}\left[M L^{-2}\right]$ & mid-distance between tile drains \\
$m_{T}\left[M L^{-2}\right]$ & amount of pesticide per unit area available in liquid phase \\
$M\left[T^{-1}\right]$ & applied amount of pesticide per unit area \\
$N_{\text {eff }}[-]$ & parameter of the SIRUP R1 reservoir \\
$Q\left[L T^{-1}\right]$ & Nash efficiency coefficient \\
$R[-]$ & drainage discharge per unit area \\
$R 1, R 2[L]$ & pesticide adsorption retardation factor \\
$T\left[L^{-1} T^{-1}\right]$ & sizes of the SIRUP R1 and R2 reservoirs \\
$w_{c}[L]$ & parameter of the SIRUP R1 reservoir \\
\hline$\theta[-]$ & water capacity of the SILASOL surface storage \\
$\lambda\left[T^{-1}\right]$ & soil volumetric water content \\
$\mu[-]$ & pesticide decay coefficient \\
$\rho_{d}\left[M L^{-3}\right]$ & drainable porosity \\
$\varphi_{1}, \varphi_{3}\left[L T^{-1}\right]$ & soil dry bulk density \\
$\phi_{i}, \phi_{r}, \phi_{\text {rain }}\left[L T^{-1}\right]$ & emptying water flows from the SIRUP reservoirs R1 and R3 \\
$\Phi\left[L T^{-1}\right]$ & infiltration, runoff and rainfall rates per unit area \\
\hline & recharge to the water table per unit area \\
\hline &
\end{tabular}




\section{References}

Abbaspour, K., Kohler, A., Simunek, J., Fritsch, M., Schulin, R., 2001. Application of a two-dimensional model to simulate flow and transport in a macroporous agricultural soil with tile drains. Eur. J. Soil Sci. 52, 433-447.

Andersen, T., Tjornhoj, R., Wollenberger, L., Slothus, T., Baun, A., 2006. Acute and chronic effects of pulse exposure of daphnia magna to dimethoate and pirimicarb. Environ. Toxicol. Chem. 25 (5), 1187-1195.

Arlot, M., 1999. Nitrate dans les eaux: drainage acteur, drainage témoin? les enseignements d'une approche hydrologique et hydraulique. Ph.D. thesis, Université Pierre et Marie Curie, Paris, France.

Augeard, B., Kao, C., Chaumont, C., Vauclin, M., 2005. Mechanisms of surface runoff genesis on a subsurface drained soil affected by surface crusting: a field investigation. Phys. Chem. Earth 30, 598-610.

Bakhsh, A., Ma, L., Ahuja, L., Hatfield, J., Kanwar, R., 2004. Using RZWQM to predict herbicide leaching losses in subsurface drainage water. Trans. ASAE 47 (5), 1415-1426.

Banton, O., Larocque, M., 1997. Agriflux 2.0 - user's manual. Tech. rep., INRS-Eau, Quebec, Canada.

Bera, P., Prasher, S., Madani, A., Gaynor, J., Tan, C., Patel, R., Kim, S., 2005. Development and field validation of the PESTFATE model in southern Ontario. Trans. ASAE 48 (1), 85-100.

Beulke, S., Brown, C., Dubus, I., Harris, G., 2001. Evaluation of uncalibrated preferential flow models against data for isoproturon movement to drains through a heavy clay soil. Pest Manag. Sci. 57 (6), 537-547.

Boesten, J., 2000. Modeller subjectivity in estimating pesticide parameters for leaching models using the same laboratory data set. Agric. Water Manage. 44, 389-409.

Boesten, J., Köpp, H., Adriaanse, P., Brock, T., Forbes, V., 2007. Conceptual model for improving the link between exposure and effects in the aquatic risk assessment of pesticides. Ecotox. Environ. Safe. 66 (3), 291308.

Bouarfa, S., Zimmer, D., 2000. Water-table shapes and drain flow rates in shallow drainage systems. J. Hydrol. 235, 264-275.

Branger, F., 2007. Utilisation d'une plate-forme de modélisation environnementale pour représenter le rôle d'aménagements hydro-agricoles sur les 
flux d'eau et de pesticides. Application au bassin versant de la Fontaine du Theil (Ille-et-Vilaine). Ph.D. thesis, Université Joseph Fourier, Grenoble, France.

Branger, F., Debionne, S., Viallet, P., Braud, I., Vauclin, M., 2006. Using the LIQUID framework to build an agricultural subsurface drainage model. In: Liong, S., Phoon, K., Babovic, V. (Eds.), 7th Hydroinformatics Int. Conf. Vol. 3. Nice, France, pp. 2024-2031.

Carluer, N., Tournebize, J., 2006. Synthèse sur les drainage et les produits phytosanitaires: analyse et modélisation des résultats expérimentaux de la Jaillière (49). Tech. rep., Ministère de l'Ecologie et du Développement Durable - Direction de l'Eau.

Dubus, I., Beulke, S., Brown, C., 2002. Calibration of pesticide leaching models: Critical review and guidance for reporting. Pest Manag. Sci. $58(8), 745-758$.

Dubus, I., Brown, C., Beulke, S., 2003. Sources of uncertainty in pesticide fate modelling. Sci. Total Environ. 317 (1-3), 53-72.

Dust, M., Baran, N., Errera, G., Hutson, J., Mouvet, C., Schafer, H., Vereecken, H., Walker, A., 2000. Simulation of water and solute transport in field soils with the LEACHP model. Agric. Water Manage. 44 (1-3), $225-245$.

EC, 2000. Directive 2000/60/EC of the European Parliament and of the Council establishing a framework for the Community action in the field of water policy.

Flury, M., 1996. Experimental evidence of transport of pesticides through field soils - a review. J. Environ. Qual. 25 (1), 25-45.

FOCUS, 2001. FOCUS surface water scenarios in the EU evaluation process under 91/414/EEC. Report of the FOCUS working group on surface water scenarios (Forum for the Coordination of Pesticide Fate Models and their Use) SANCO/4802/2001-rev2.

Giraud, F., Faure, J., Zimmer, D., Lefeuvre, J., Skaggs, R., 1997. Hydrologic modeling of a complex wetland. J. Irrig. Drain. E-ASCE 123 (5), 344-353.

Gärdenäs, A., Simunek, J., Jarvis, N., van Genuchten, M. T., 2006. Twodimensional modelling of preferential water flow and pesticide transport from a tile-drained field. J. Hydrol. 329, 647-660.

Gustafson, D., 1989. Groundwater Ubiquity Score: a simple method for assessing pesticide leachability. Environ. Toxicol. Chem. 8, 339-357. 
Hartani, T., Zimmer, D., Lesaffre, B., 2003. Drainage of sloping lands with variable recharge model validation and applications. J. Irrig. Drain. EASCE 129 (4), 284-290.

Heng, L., White, R., Scotter, D., Bolan, N., 1994. A transfer function approach to modelling the leaching of solutes to subsurface drains. II. Reactive solutes. Aust. J. Soil Res. 32 (1), 85-94.

Hooghoudt, S., 1940. Hooghoudt's theory of drainage. Tech. rep., Institut voor Cultuurtechnik en Waterhuishouding, The Netherlands.

IFEN, 2006. Pesticides in water: 2003 and 2004 data. Tech. Rep. Les dossiers 5, Institut Français de l'Environnement, France.

Jury, W., 1982. Simulation of solute transport using a transfer function model. Water Resour. Res. 18, 363-368.

Jury, W., Roth, K., 1990. Transfer functions and solute movement through soil: theory and applications. Birkhäuser Verlag.

Kalita, P., Ward, A., Kanwar, R., McCool, D., 1998. Simulation of pesticide concentrations in groundwater using Agricultural Drainage and Pesticide Transport (ADAPT) model. Agric. Water Manage. 36 (1), 23-44.

Kao, C., Nédélec, Y., Zimmer, D., 1998. Surface runoff mechanisms and modeling in subsurface drained fields. In: Brown, L. (Ed.), 7th Annual Drainage Symposium "Drainage in the 21st century: Food Production and Environment". Vol. 7. ASAE, Orlando, USA, pp. 258-266.

Kladivko, E., Brown, L., Baker, J., 2001. Pesticide transport to subsurface tile drains in humid regions of North America. Crit. Rev. Environ. Sci. Technol. 31 (1), 1-62.

Kladivko, E., Van Scoyoc, G., Monke, E. J., Oates, K., Pask, W., 1991. Pesticide and nutrient movement into subsurface tile drains on a silt loam soil in Indiana. J. Environ. Qual. 20, 264-270.

Kumar, A., Kanwar, R., 1997. Incorporating preferential flow and herbicide fate and transport into the DRAINAGE model. Trans. ASAE 40 (4), 977985.

Larsbo, M., Jarvis, N., 2003. MACRO 5.0: a model for water flow and solute transport in macroporous soil. Tech. rep., Swedish University of Agricultural Sciences.

Leistra, M., van der Linden, A., Boesten, J., Tiktak, A., van den Berg, F., 2001. PEARL model for pesticide behaviour and emissions in soil-plant systems. Description of processes. Tech. Rep. RIVM report 711401009, Alterra, Wageningen. 
Leonard, R., Knisel, W., Davis, F., 1995. Modelling pesticide fate with GLEAMS. Eur. J. Agron. 4 (4), 485-490.

Lesaffre, B., Zimmer, D., 1988. Subsurface drainage peak flows in shallow soil. J. Irrig. Drain. E-ASCE 114 (3), 387-406.

Madrigal, I., 2004. Rétention de pesticides dans les sols des dispositifs tampon, enherbés et boisés - Rôle des matières organiques. Ph.D. thesis, INAPG, Paris, France.

Madrigal, I., Benoit, P., Barriuso, E., Etiévant, V., Souiller, C., Réal, B., Dutertre, A., 2002. Sorption properties of two herbicides: Isoproturon and Diflufenican in different grassed buffer strip soils. Etude et Gestion des Sols 9 (4), 287-302.

Magesan, G., Scotter, D., White, R., 1994. A transfer function approach to modelling the leaching of solutes to subsurface drains I. Non-reactive solutes. Aust. J. Soil Res. 32 (1), 69-83.

Nash, J., Sutcliffe, J., 1970. River flow forecasting through conceptual models. J. Hydrol. 167 (1-4), 167-174.

Paris, T., 2004. Etude du transfert d'eau et de solutés dans un sol à nappe superficielle drainée artificiellement. Ph.D. thesis, Ecole Nationale du Génie Rural, des Eaux et des Forêts, Paris, France.

Rudra, R., Negi, S., Gupta, N., 2005. Modelling approaches for subsurface drainage water quality management. Water Qual. Res. J. Can. 40 (1), $71-81$.

Scorza Jr., R., Jarvis, N., Boesten, J., Van Der Zee, S., Roulier, S., 2007. Testing MACRO (version 5.1) for pesticide leaching in a Dutch clay soil. Pest Manag. Sci. 63 (10), 1011-1025.

Scotter, D., Heng, L., White, R., 1991. Two models for the leaching of a non-reactive solute to a mole drain. J. Soil Sci. 42 (4), 565-576.

Scotter, D., White, R., Dyson, J., 1993. The Burns leaching equation. J. Soil Sci. 44 (1), 25-33.

Simunek, J., Sejna, M., van Genuchten, M., 1999. The HYDRUS-2D software package for simulating the two-dimensional movement of water, heat and multiple solutes in variably-saturated media. Tech. rep., International Groundwater Modelling Center - Colorado School of Mines, USA.

Skaggs, R., 1999. Drainage simulation models. In: Skaggs, R., van Schilfgaarde, J. (Eds.), Agricultural Drainage. ASA-CSSA-SSSA, Madison, Wisconsin, USA, pp. 469-500. 
Paper published in Agricultural Water Management 96 (2009) 415-428

Stewart, I., Loague, K., 1999. A type transfer function approach for regionalscale pesticide leaching assessments. J. Environ. Qual. 28 (2), 378-387.

Tiemeyer, B., Moussa, R., Lennartz, B., Voltz, M., 2007. MHYDAS-DRAIN: A spatially distributed model for small, artificially drained lowland catchments. Ecol. Model. 209 (1), 2-20.

Tiktak, A., Boesten, J., van der Linden, A., Vanclooster, M., 2006. Mapping ground water vulnerability to pesticide leaching with a process-based metamodel of EuroPEARL. J. Environ. Qual. 35, 1213-1126.

Van Ommen, H., 1985a. The 'mixing-cell' concept applied to transport of non-reactive and reactive components in soils and groundwater. J. Hydrol. 78 (3-4), 201-213.

Van Ommen, H., 1985b. Systems approach to an unsaturated-saturated groundwater quality model, including adsorption, decomposition and bypass. Agric. Water Manage. 10, 193-203.

Van Ommen, H., Van Genuchten, M., Van Der Molen, W., Dijksma, R., Hulshof, J., 1989. Experimental and theoretical analysis of solute transport from a diffuse source of pollution. J. Hydrol. 105 (3-4), 225-251.

Vanclooster, M., Boesten, J., Trevisan, M., Brown, C., Capri, E., Eklo, O., Gottesburen, B., Gouy, V., Van der Linden, A., 2000. A European test of pesticide-leaching models: Methodology and major recommendations. Agric. Water Manage. 44 (1-3), 1-19.

Viallet, P., Debionne, S., Braud, I., Dehotin, J., Haverkamp, R., Saâdi, Z., Anquetin, S., Branger, F., Varado, N., 2006. Towards multi-scale integrated hydrological models using the LIQUID framework. In: Liong, S., Phoon, K., Babovic, V. (Eds.), 7th Hydroinformatics Int. Conf. Vol. 1. Nice, France, pp. 542-549.

Vinten, A., Vivian, B., Redman, M., 1991. An analysis of the leaching of chloride tracer applied to pipe- drained plots using a coupled unsaturatedsaturated zone model of solute transport. Soil Use Manage. 7 (2), 103-109.

White, R., Heng, L., Magesan, G., 1998. Nitrate leaching from a drained, sheep-grazed pasture II. Modelling nitrate leaching losses. Aust. J. Soil Res. 36, 963-977.

Zehe, E., Flühler, H., 2001. Preferential transport of isoproturon at a plot scale and a field scale tile-drained site. J. Hydrol. 247 (1-2), 100-115.

Zimmer, D., 2001. Hydrologie de surface des zones à nappes superficielles. Mémoire d'habilitation à diriger des recherches, Université Pierre et Marie Curie, Paris, France. 
Zimmer, D., Lorre, E., Lesaffre, B., 1995. Parameter sensitivity and field evaluation of SIDRA model. Irrig. Drain. Syst. 9, 279-296. 


\begin{tabular}{|c|c|c|c|c|c|c|}
\hline Herbicide & $\begin{array}{l}\text { Pressure } \\
(\mu \mathrm{Pa})\end{array}$ & $\begin{array}{l}\begin{array}{l}\text { Solubility } \\
(\mathrm{mg} / \mathrm{L})\end{array} \\
\end{array}$ & $K_{o c}(\mathrm{~L} / \mathrm{kg})$ & $K_{d}(\mathrm{~L} / \mathrm{kg})$ & $\begin{array}{l}\text { DT50 } \\
\text { (days) }\end{array}$ & $\begin{array}{l}\text { GUS } \\
(-)\end{array}$ \\
\hline \multirow[t]{3}{*}{ IPU } & $\underline{3.3}$ & $\underline{70}$ & $\underline{36-241}$ & & $\underline{12-33}$ & 2.51 \\
\hline & & & $141-155$ & $1.0-2.3$ & & \\
\hline & & & $129-144$ & $1.0-2.2$ & & \\
\hline \multirow[t]{3}{*}{$\mathrm{DFF}$} & $\underline{31}$ & $\leq 0.05$ & $\underline{1622-2369}$ & & $\underline{90-270}$ & 1.58 \\
\hline & & & $2508-4442$ & 20.1-63.6 & & \\
\hline & & & 3027-6315 & 24.2-90.4 & & \\
\hline
\end{tabular}

Table 1: Main chemical and physical properties of the two herbicides IPU and DFF: saturated vapor pressure, solubility at $22^{\circ} \mathrm{C}$, sorption coefficient on organic matter $\left(K_{o c}\right)$, soil-water partition coefficient $\left(K_{d}\right)$, half-life (DT50) and GUS leaching index (Gustafson, 1989). Data sources are the AGRITOX database (underlined) and measurements on undisturbed soil samples collected at La Jaillière for different horizons of the soil first $60 \mathrm{~cm}$ (resp. Madrigal et al., 2002 in italic and Madrigal, 2004 in bold). 


\begin{tabular}{ll}
\hline Parameter and description & Value \\
\hline SIDRA & \\
$K\left(m s^{-1}\right)$ & $5.8 \times 10^{-6}$ \\
$\mu(-)$ & $\underline{0.01}$ \\
$A_{1}(-)$ & 0.86 \\
$A_{2}(-)$ & 0.9 \\
\hline SIRUP & \\
$R 1(m)$ & $\underline{0.005}$ \\
$T\left(m^{-1} s^{-1}\right)$ & $\underline{1.39 \times 10^{-4}}$ \\
$M\left(s^{-1}\right)$ & $\underline{4.17 \times 10^{-5}}$ \\
$R 2(m)$ & $\underline{0.005}$ \\
$B\left(s^{-1}\right)$ & $\underline{3.0 \times 10^{-5}}$ \\
\hline SILASOL & $\underline{0.15}$ \\
$w_{c}(m)$ & 0.86 \\
$c_{1}(-)$ & 0.14 \\
$c_{2}(-)$ & $\underline{0.2}$ \\
$a_{1}(\mathrm{~m})$ & $\underline{1.0} \times 10^{-4}$ \\
$a_{2}(\mathrm{~m})$ & $4.6(\mathrm{IPU})$ \\
$\mathrm{R}(-)$ & $79.7(\mathrm{DFF})$ \\
$\lambda\left(s^{-1}\right)$ & $3.6 \times 10^{-7}(\mathrm{IPU})$ \\
& $4.4 \times 10^{-8}(\mathrm{DFF})$ \\
\hline
\end{tabular}

Table 2: Parameter set. $K$ is the saturated hydraulic conductivity, $\mu$ is the drainable porosity, $A_{1}$ and $A_{2}$ are the water table shape factors. $R 1$ and $R 2$ are the sizes of the SIRUP reservoirs R1 and R2, T, $M$ and $B$ are conceptual parameters. $w_{c}$ is the water capacity of SILASOL soil surface storage, $c_{1}$ and $c_{2}$ are the relative contributions of the two transfer function compartments, $a_{1}$ and $a_{2}$ are the transfer function parameters. $R$ and $\lambda$ are the pesticide retardation factor and decay coefficient, respectively. The underlined values were calibrated. The other parameters were set using field or literature data.

\begin{tabular}{llllll}
\hline & Drainage & & \multicolumn{2}{c}{ Surface runoff } \\
& $\operatorname{sim}(\mathrm{mm})$ & obs $(\mathrm{mm})$ & $N_{\text {eff }}$ & $\operatorname{sim}(\mathrm{mm})$ & obs $(\mathrm{mm})$ \\
\hline $1995-1996$ & 87 & 93 & 0.57 & 18 & 8 \\
\hline $1999-2000$ & 241 & 222 & 0.69 & 31 & 25 \\
\hline
\end{tabular}

Table 3: Validation data of the PESTDRAIN model for water flow (1999-2000 and 1995-1996 seasons). Cumulative values of surface runoff and drainage are given in $\mathrm{mm} ; N_{\text {eff }}$ is the Nash-Sutcliffe efficiency coefficient for drainage flow. 


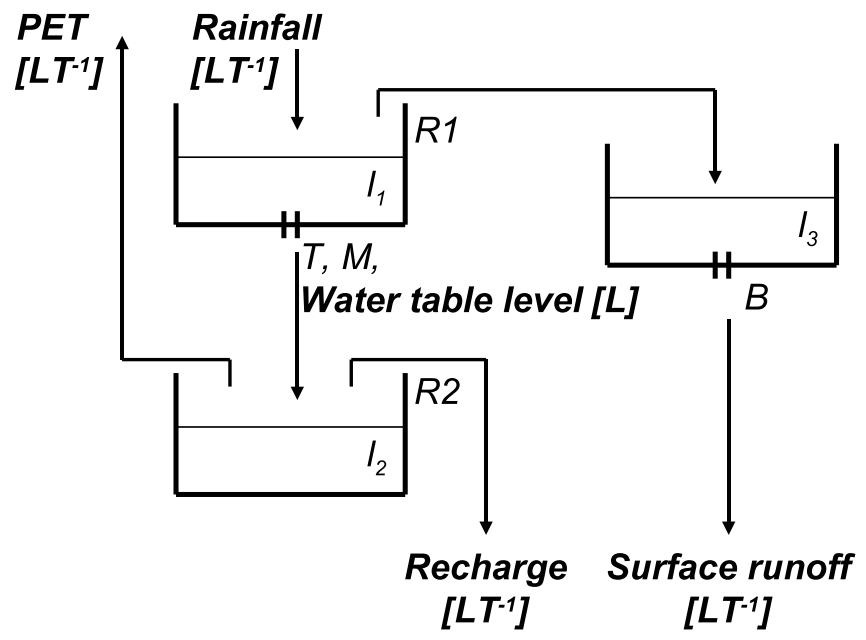

Figure 1: Structure of the SIRUP module. $l_{1}, l_{2}$ and $l_{3}$ are the water levels in the reservoirs; $R 1$ and $R 2$ are the sizes of Reservoir 1 and Reservoir 2, respectively; $\mathrm{T}$, $\mathrm{M}$ and $\mathrm{B}$ are the parameters of the emptying laws for Reservoir 1 and Reservoir 3; $\mathrm{PET}$ is the potential evapotranspiration. 


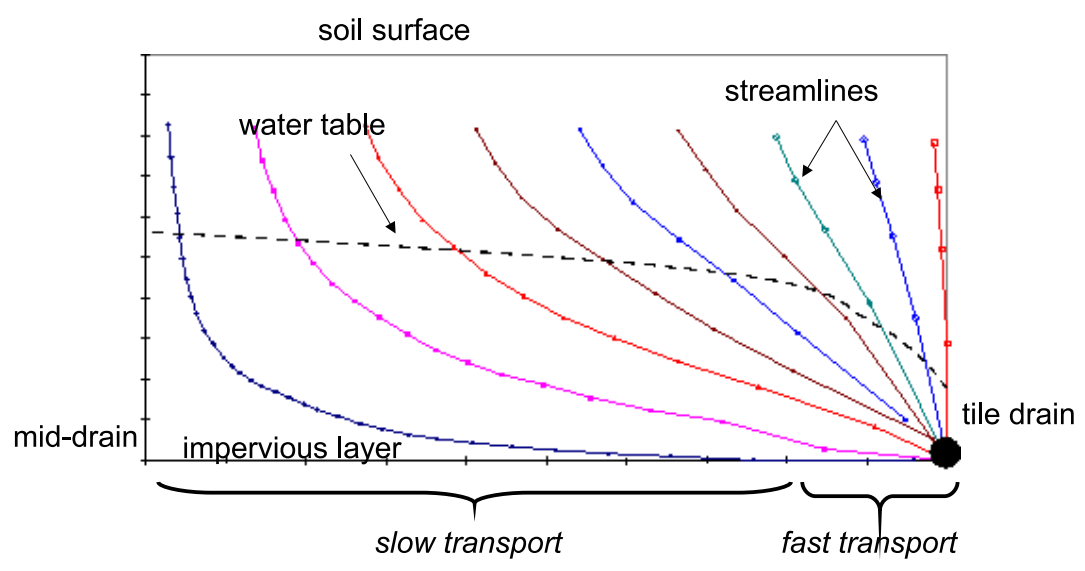

Figure 2: Example of streamlines in a tile-drained soil profile for a pulse of nonreactive solute under steady hydrodynamical conditions (Paris, 2004). Each interval between two marks on a streamline corresponds to a one-hour time step.

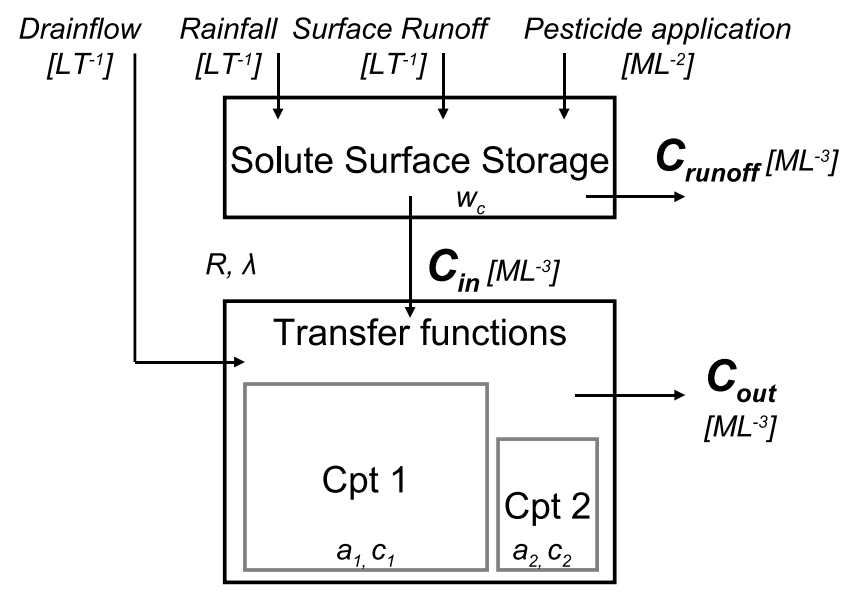

Figure 3: Structure of the SILASOL module. The compartments Cpt1 and Cpt2, respectively account for slow and fast solute transport to the tile drain. SILASOL requires seven parameters which are the pesticide adsorption retardation factor $R$, the pesticide decay coefficient $\lambda$, the solute surface storage water capacity $w_{c}$, the compartments transfer function coefficients $a_{1}$ and $a_{2}$ and the compartments relative contributions $c_{1}$ and $c_{2}$. 


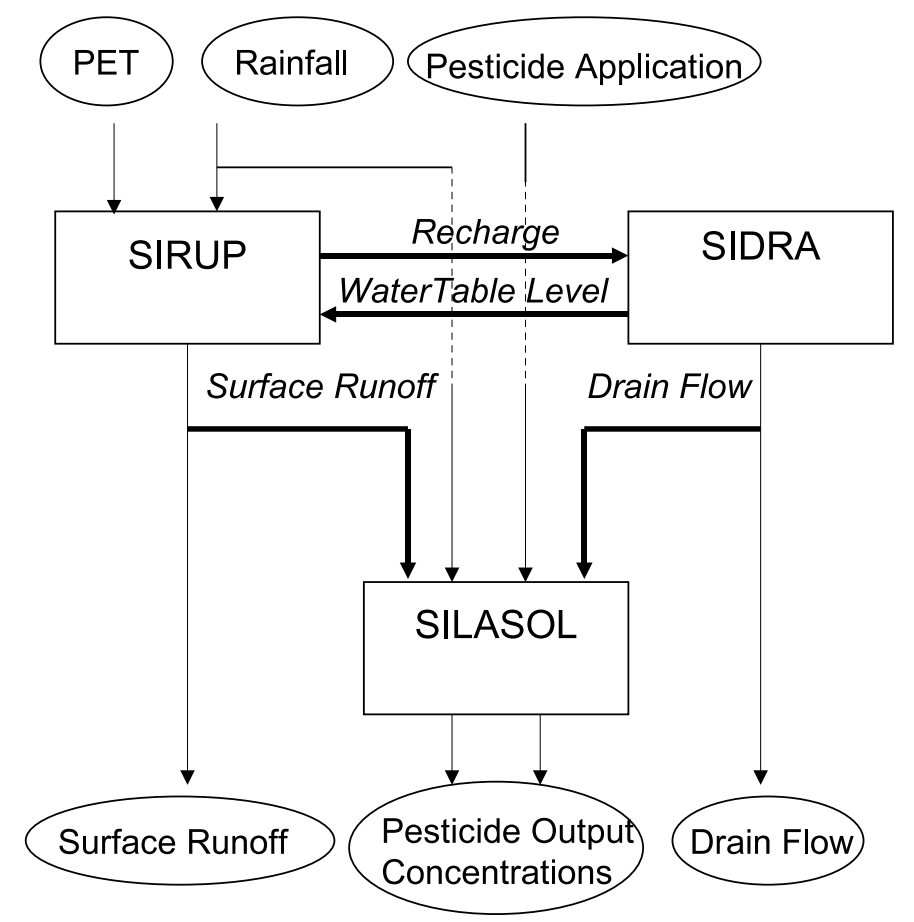

Figure 4: Structure of the PESTDRAIN model: inputs, outputs and couplings between the three modules SIDRA, SIRUP and SILASOL. PET is the potential evapotranspiration. 

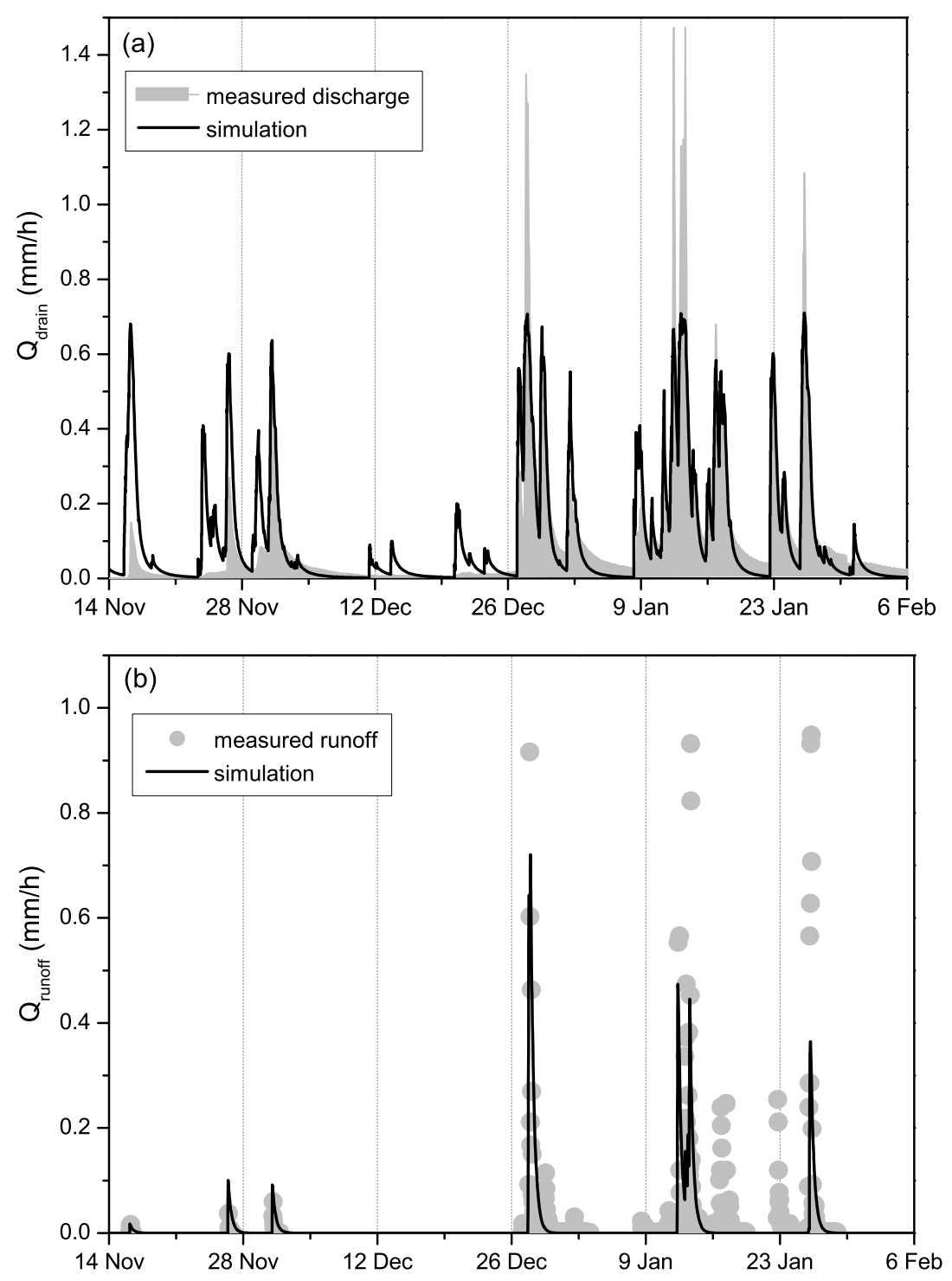

Figure 5: Calibration period (2003-2004) data: (a) drainage discharge; (b) surface runoff. 

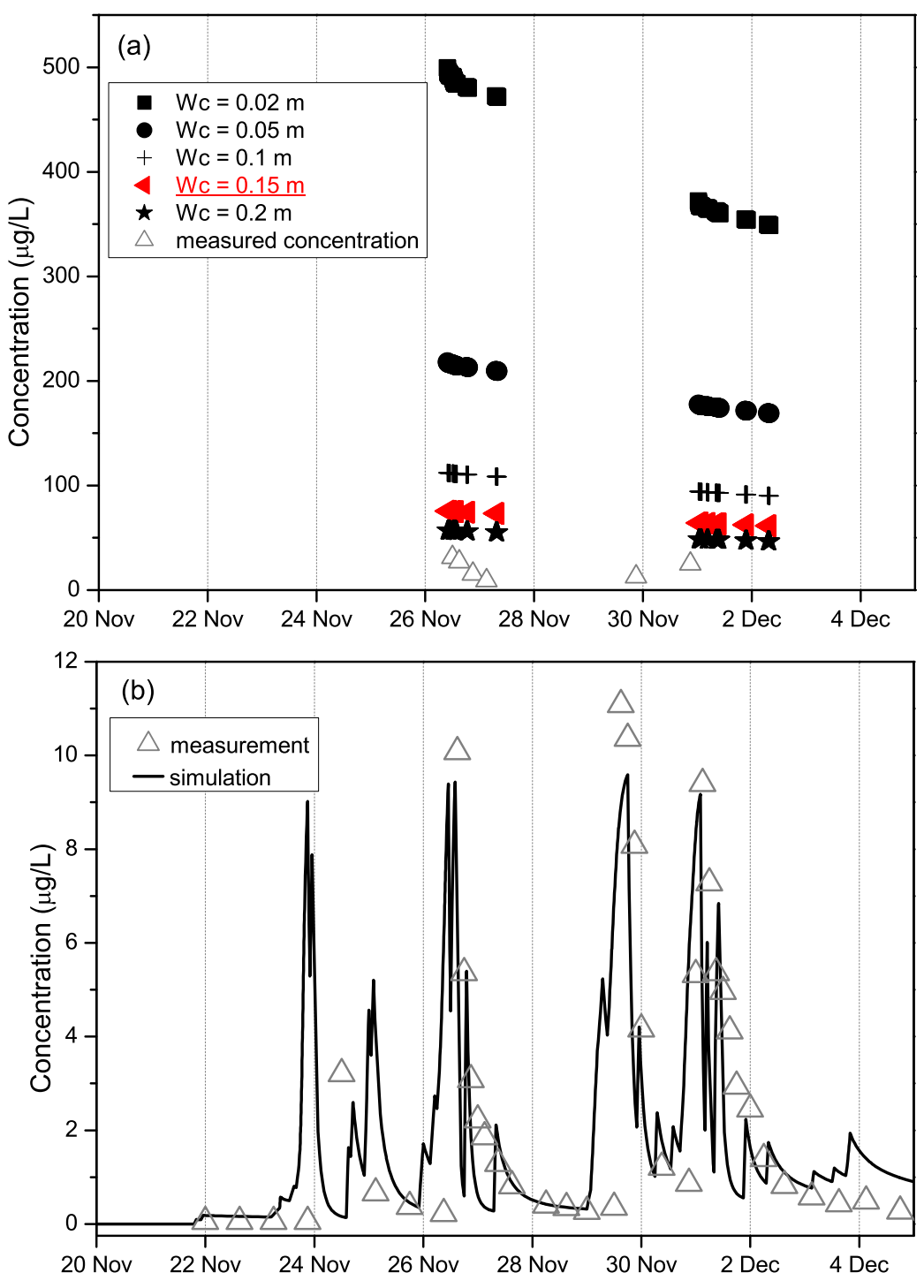

Figure 6: Calibration results for pesticide transport (isoproturon): (a) comparison between measurements and simulations in surface runoff for several values of the water capacity $w_{c}$ and (b) comparison between measurements and simulations in drainage. 

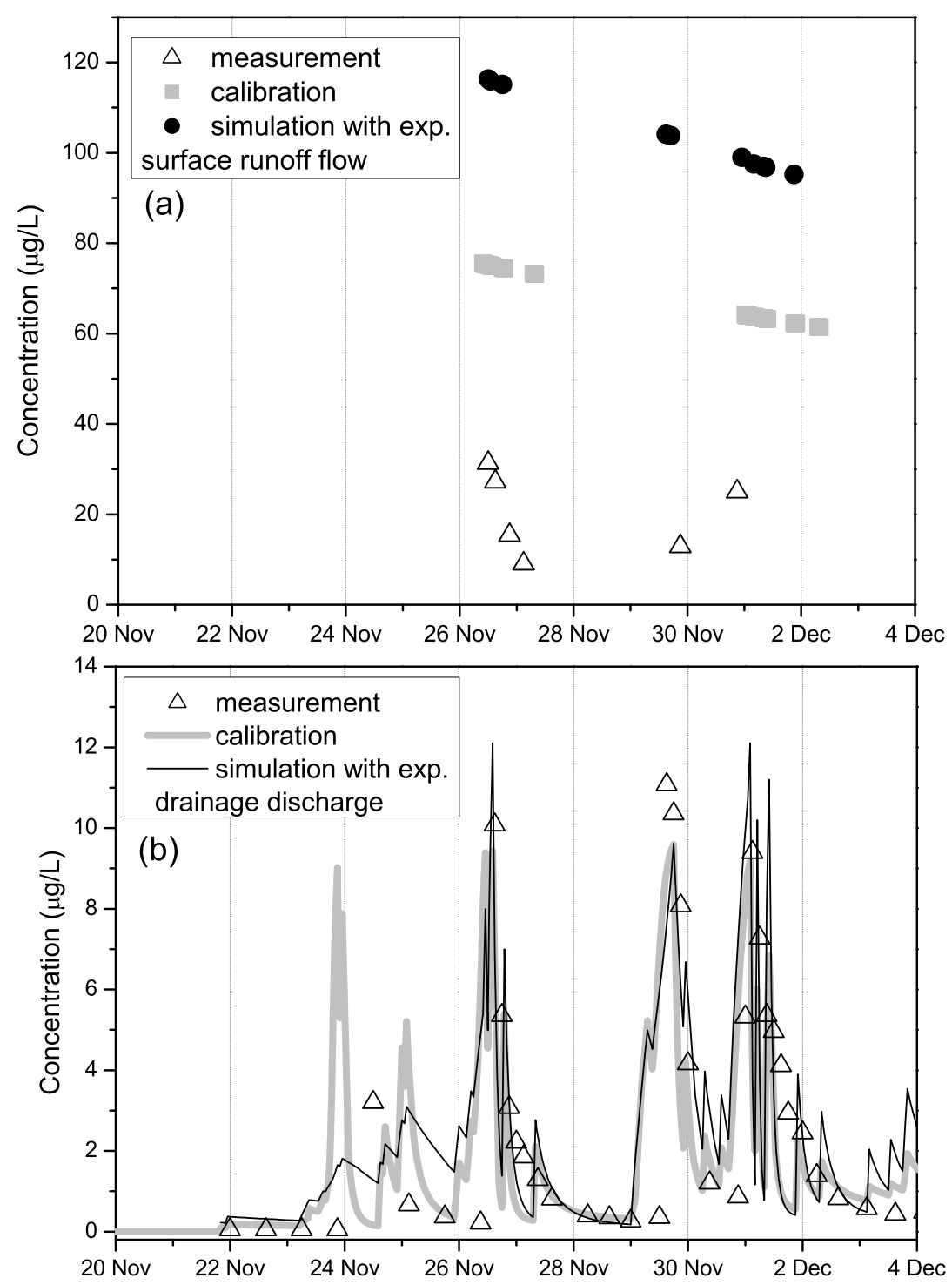

Figure 7: Standalone simulations of SILASOL for the calibration data set in order to study compensations: comparison between the measured IPU concentrations, the previously calibrated values and the values obtained: (a) by replacing the simulated surface runoff flow by the measurements and (b) by replacing the simulated drainage discharge by the measurements. 


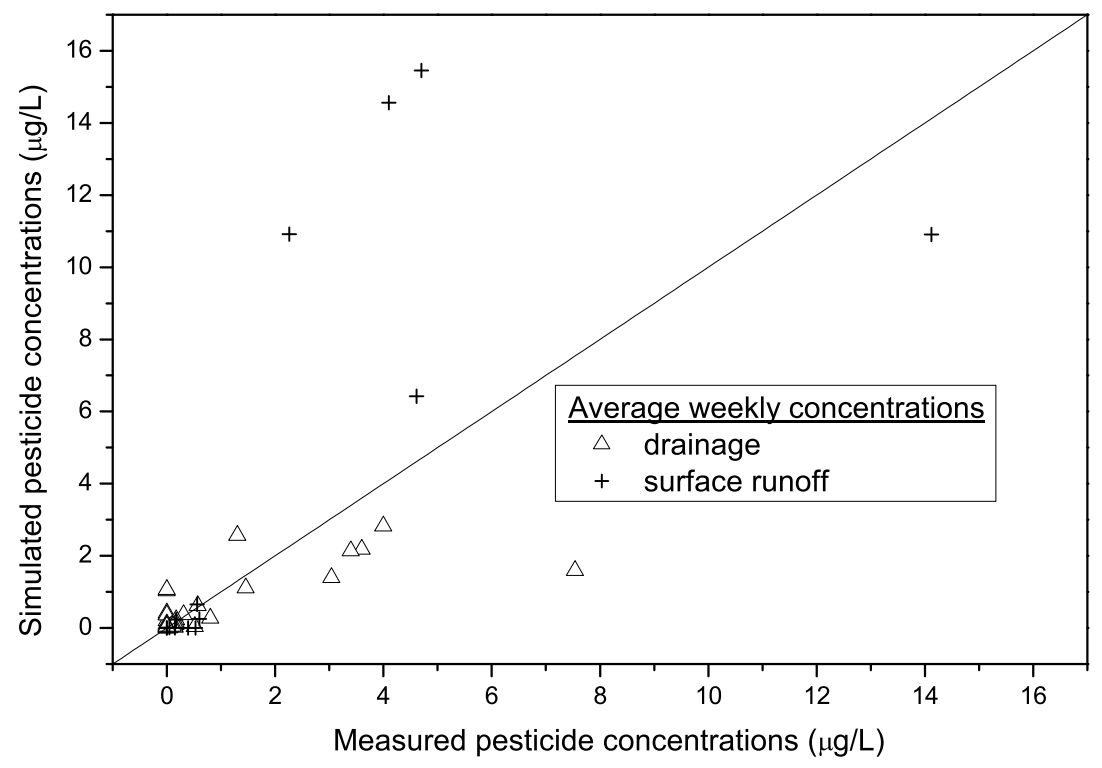

Figure 8: Validation data for pesticide transport: comparison between simulated and measured concentrations in drainage and surface runoff, for both 1995-1996 and 1999-2000 validation periods and for both molecules IPU and DFF. 

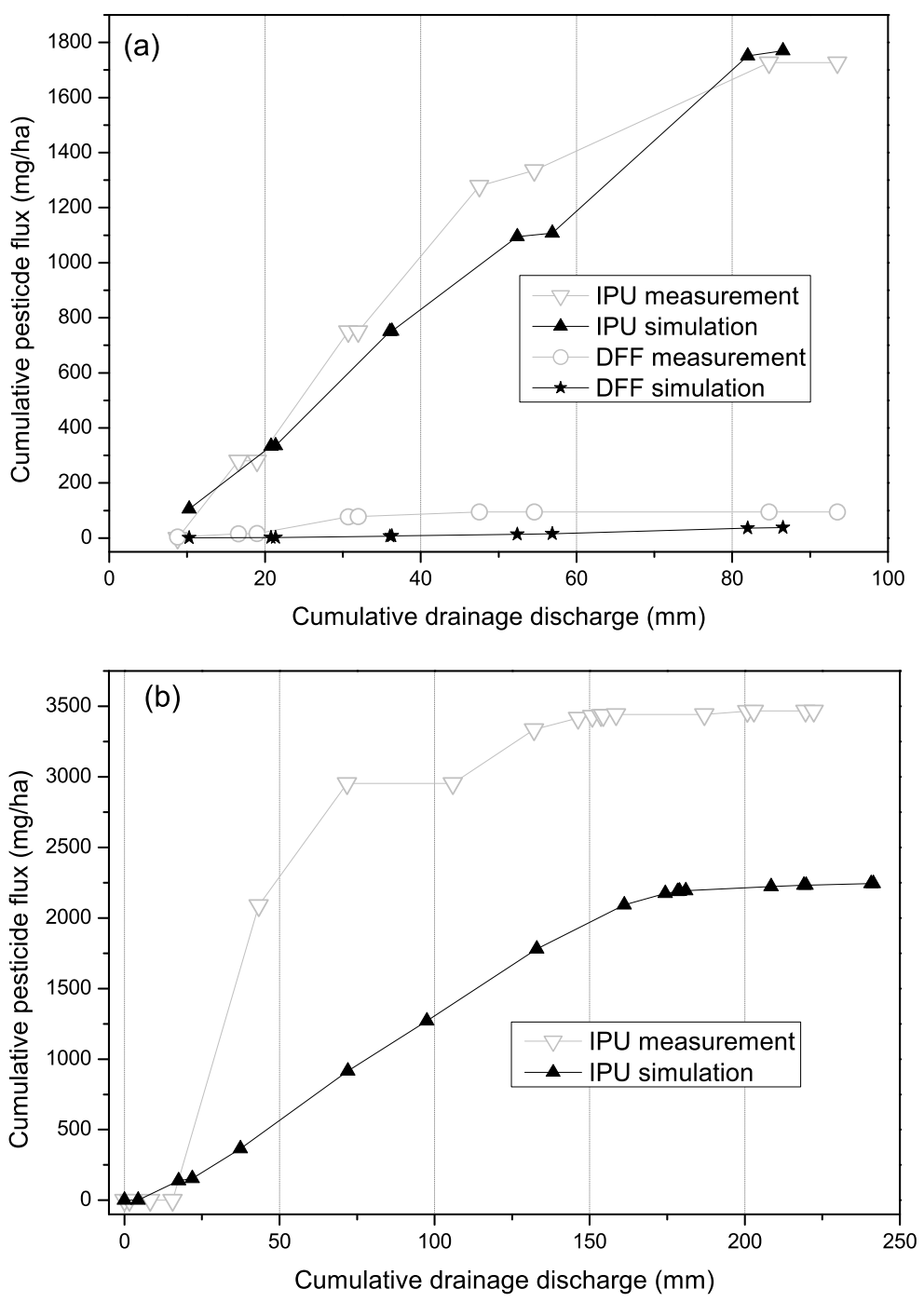

Figure 9: Validation data for pesticide transport in drainage: measured and simulated cumulative pesticide fluxes as functions of cumulative drainage discharge for the 1995-1996 (a) and 1999-2000 (b) validation periods. 

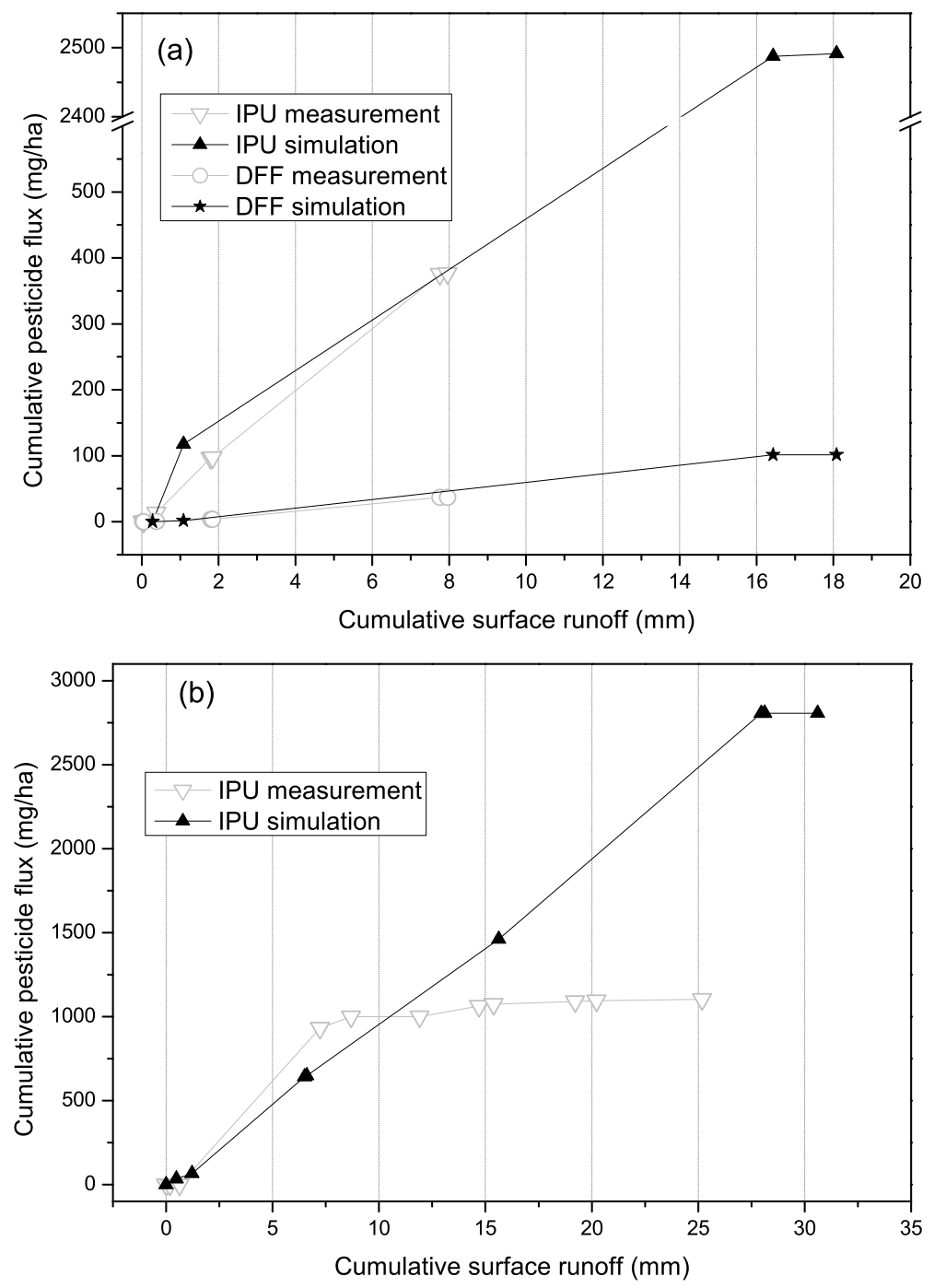

Figure 10: Validation data for pesticide transport in surface runoff: measured and simulated cumulative pesticide fluxes as functions of cumulative runoff for the 1995-1996 (a) and 1999-2000 (b) validation periods. 